\title{
Influence of specific training on spatio-temporal parameters at the onset of goal-directed reaching in infants: a controlled trial*
}

\author{
Andréa B. Cunha ${ }^{1}$, Marjorie Woollacott ${ }^{2}$, Eloisa Tudella $^{1}$
}

\begin{abstract}
Background: There is evidence that long-term experience can promote functional changes in infants. However, much remains unknown about how a short-term experience affects performance of a task. Objective: This study aims to investigate the influence of a single training session at the onset of goal-directed reaching on the spatio-temporal parameters of reaching and whether there are differences in the effects of training across different reaching positions. Method: Thirty-three infants were divided into three groups: 1) a control group; 2) a group that was reach trained in a reclined position; and 3) a group trained in the supine position. The infants were submitted to two assessments (preand post-training) in two testing positions (supine and reclined at $45^{\circ}$ ). Results: The short-duration training sessions were effective in promoting shorter reaches in the specific position in which the training was conducted. Training in the reclined position was associated with shorter and faster reaches upon assessment in the reclined position. Conclusions: A few minutes of reach training are effective in facilitating reaching behavior in infants at the onset of reaching. The improvements in reaching were specific to the position in which the infants were trained.
\end{abstract}

Keywords: physical therapy; kinematics; posture; training; reaching; infant. Registered in the Australian Clinical Trials Registry (no.: ACTRN12610000818033).

\section{HOW TO CITE THIS ARTICLE}

Cunha AB, Woollacott M, Tudella E. Influence of specific training on spatio-temporal parameters at the onset of goal-directed reaching in infants: a controlled clinical trial. Braz J Phys Ther. 2013 July-Aug; 17(4):409-417. http://dx.doi.org/10.1590/ S1413-35552012005000099

\section{Introduction}

In full-term infants, reaching is acquired at approximately 3-4 months of age $\mathrm{e}^{1-4}$. This period is characterized by fragmented and irregular trajectories, abrupt movements of the hands $s^{3,5}$ and movements structured with several phases of acceleration and deceleration ${ }^{2}$, indicating a lack of coordination and imature motor control. This first phase of reaching is known as the phase of primary variability, and the process of continuous exploration with efferent information gradually results in the formation of new neuronal maps and the selection of more efficient movement patterns ${ }^{6-10}$.

With experience, the motor system becomes able to adapt to different environmental conditions and tasks ${ }^{11}$; thus, reaches became more regular, with more fluent trajectories ${ }^{12-14}$ and less variability ${ }^{3,5}$. In studies with full-term and preterm infants, reach training for 2-8 weeks led to improvements, such as reliably moving the hands closer to the object and increasing the time the hands are near the object, the number of contacts between the hand and the object ${ }^{15}$, and the frequency of touching the object with an open hand ${ }^{16}$. These findings suggest that interventions to improve motor patterns had a more beneficial effect when performed in a specific training context $\mathrm{t}^{17-19}$.

However, it is interesting to observe that these studies do not report whether a short period of practice could influence spatio-temporal parameters of reaching movements. Regarding short practice periods, some authors have studied a training session of a few minutes in sequential finger opposition training in adults at the time of early motor skill acquisition $^{20,21}$. It has been shown that during this short period of practice, specific sensorimotor representations in the cerebral cortex are activated, including the striatum and cerebellum ${ }^{21,22}$, with a concomitant rapid improvement in the performance of a given ability ${ }^{23}$. This evidence could provide a basis for the consolidation of the performance of a specific task in the early stages of learning ${ }^{21}$.

\footnotetext{
${ }^{1}$ Neuropediatrics Sector, Department of Physical Therapy, Universidade Federal de São Carlos (UFSCar), São Carlos, SP, Brazil

${ }^{2}$ Institute of Neuroscience, University of Oregon (UO), Portland, OR, United States

*This study was presented at the VI Brazilian Congress of Motor Behavior, São Paulo, July 2012, including publication of the abstract.

Received: 11/29/2012 Revised: 12/20/2012 Accepted: 01/20/2013
} 
Another important factor affecting early reaching behavior is body position. It has been shown that body position at the time of spontaneous practice also influences the increase in frequency and coordination of reaches in younger infants ${ }^{24}$. Moreover, reaching training in the supine position for 3 weeks can enhance the number and duration of object contacts in both the sitting and supine positions ${ }^{19}$. However, there are no studies reporting whether training sessions in a supine position compared to a reclined position could influence spatio-temporal parameters of the reaching.

In this context, this study aimed to a) determine the effect of short-duration training sessions performed in a supine or reclined position on spatio-temporal parameters at the onset of goal-directed reaching and $b$ ) to assess changes in these parameters from one position to another. Based on previous information, the first hypothesis was that trained infants would exhibit shorter, faster and smoother reaching movements compared to the control group. The second hypothesis was that there would be no changes in spatio-temporal parameters that could be generalized across the two positions. This study provides information to health professionals and/ or caregivers about how to improve sensorimotor development in infants at risk for delays or deficits in motor development.

\section{Method}

\section{Design and participants}

This study is characterized as a controlled clinical trial. The sample size calculation was performed for a confidence interval of $95 \%$ and power of $80 \%$, and a minimum number of 8 participants for each group was determined.

The study included 33 full-term infants in maternal care ( $M=39.0$ weeks of gestation \pm 1.1$)$, aged 3-4 months $(M=13.1$ weeks \pm 1.1$)$, from both genders ( 18 females and 15 males), with Apgar scores ${ }^{25}$ greater than or equal to eight in the first $(M=8.8 \pm 0.5)$ and fifth minutes $(M=9.8 \pm 0.4)$ and mean birth weight ${ }^{26}$ of $2.920 \mathrm{~kg}( \pm 0.9)$. The infants were systematically assigned to 1$)$ a control group $(\mathrm{n}=11) ; 2)$ a group trained in the reclined position ( $\mathrm{n}=11)$; and 3) a group trained in the supine position $(\mathrm{n}=11)$.

\section{Procedures and equipment}

The study was approved by the Ethics Committee of the Universidade Federal de São Carlos (UFSCar), São Carlos, SP, Brazil (no.: 516/2009), and was prospectively registered in the Australian Clinical Trials Registry (no.: ACTRN12610000818033).

From the week before the infants' three-month birthday, the examiner made contact by phone with the parents. After the parents signed an informed consent form, it was explained to them that reaching is the act of locating an object in space, directing visual attention toward the object and directing one or both hands to it and touching it. The parents were asked to assist in identifying the precise day of the infants' reaching onset. Regardless of parents' calls, the examiner made a visit to their residence twice weekly to aid in identifying the precise day on which the infant acquired the reaching movement.

Once confirmed, the Alberta Infant Motor Scale (AIMS) was administered and scored by a single pediatric physical therapist at the infant's home. The AIMS was used to ensure that all infants were similar in their motor development (percentile between 25 and 75 of the AIMS's normative curve $)^{27}$ at reaching onset.

After the AIMS assessment, a kinematic assessment was scheduled at the laboratory, which occurred no later than three days after this visit $(M=2.4$ days \pm 1.09$)$. Three cameras were used for kinematic analysis (frequency of $60 \mathrm{~Hz}$ ), two located posterior-laterally and one located posteriorsuperiorly to the infant. A fourth camera, located anterior-superiorly to the infant, was used to confirm that the infant's visual attention was directed toward the toy during reaches.

The images were digitalized using the Dvideow system $5.0{ }^{28-30}$. To filter the results released by the system and to calculate the spatio-temporal variables, Matlab system 7.9 was used. A $4^{\text {th }}$-order digital Butterworth filter with a cutoff frequency of $6 \mathrm{~Hz}$ was used. The calibration system used was similar to that developed by Carvalho et al..$^{30}$ (volume $=62.5$ $\mathrm{cm} \times 50.5 \mathrm{~cm} \times 41.5 \mathrm{~cm}$ ).

\section{Testing procedure}

All of the infants were submitted to two assessments carried out in sequence on a single day: a pre-training assessment (performed before the training session), and a post-training assessment (performed immediately after the training session).

The infants were in diapers and in an active alert state $^{31}$ for the pre-training assessment. A reflective marker was fixed on the infant's wrist between the styloid process of the radius and ulna ${ }^{14}$. The infant was placed in a baby chair and the examiner used his hands to support the infant at the height of the xiphoid process to provide security and truncal 
stability. An interval of 20 seconds was allowed for the infant to adapt to the situation, during which no stimulus was given ${ }^{24}$. To encourage the reaching movement, an unfamiliar toy made of attractive, soft latex was shown to the infant. The toy was held by the examiner, who was positioned at the infant's midline within reaching distance for 2 minutes and was always oriented vertically along its major axis ${ }^{32}$. During this period, the toy was carefully taken away and presented again after each successful toy contact (reach). A 5-s interval was allowed between reaches. Thus, the total number of reaches depended on the infant. If the infant was not interested in the object offered, another one with the same physical characteristics but a different color was presented.

The pre-training consisted of two procedures: 1) Procedure A: infants were placed in a seated position reclined $45^{\circ}$ from the horizontal (Figure 1A), and 2) Procedure B: infants were placed in a supine position (Figure 1B). Each procedure lasted 2 minutes with an interval of approximately 30 seconds between them. The total time of the two testing procedures was 4 minutes and 30 seconds. If the infant cried or was irritable between the procedures, more time was offered, so that the infant could be held by the parents. If the infant persisted, the experiment was terminated. The infants were assigned to procedure A or B by a coin flip for randomization. The post-training test was identical to the pre-training test.

\section{Reaching training protocol}

The control group received no training or stimuli and remained in their parents' lap for 4 minutes. Both training groups received a single, shortduration reach training session (approximately 4 minutes), which was administered by the examiner (a pediatric physical therapist). For the training session of the group trained in the reclined position (approximately $45^{\circ}$ in relation to the floor), the examiner sat with her trunk supported, legs slightly apart, and hips and knees flexed approximately $120^{\circ}$ and $50^{\circ}$, respectively. A small pillow was placed on her knees. The infant's head was placed on the pillow. This allowed the infant to remain face to face with the examiner with his/her neck in semiflexion, thus facilitating the alignment between the head and trunk. The infant's hands were kept near the midline, within the infant's visual field. For the group trained in the supine position, the infant was placed in a supine position on a mat for the training session (Figure 2A-B).

The training sessions in the supine and reclined positions were each composed of 3 activities (Table 1). This training protocol was based on studies by Lobo et al. ${ }^{15}$, Heathcock et al. ${ }^{16}$ and Soares et al. ${ }^{33}$. The same object was used for the assessment that was used for the training. Each activity had a duration of approximately 80 seconds under blocked practice conditions, i.e., the practice for each activity was completed before the next was initiated ${ }^{34-36}$.

\section{Description of variables}

Reaching was considered when the infant located the object in space, directed visual attention toward it and touched the object with one or both arms facing the object ${ }^{14}$. The beginning of a reach was defined as the first frame when the infant's arm began an uninterrupted movement toward the object. The end of a reach was defined as the first frame when the infant's hand touched the object ${ }^{12,32}$.

The coding of reaches was performed blindly to avoid bias in the results. The mean value for all inter-rater agreement among three observers was $90.0 \%$ for reaches and $93.5 \%$ for AIMS. It was calculated for $12.5 \%$ of the total sample using
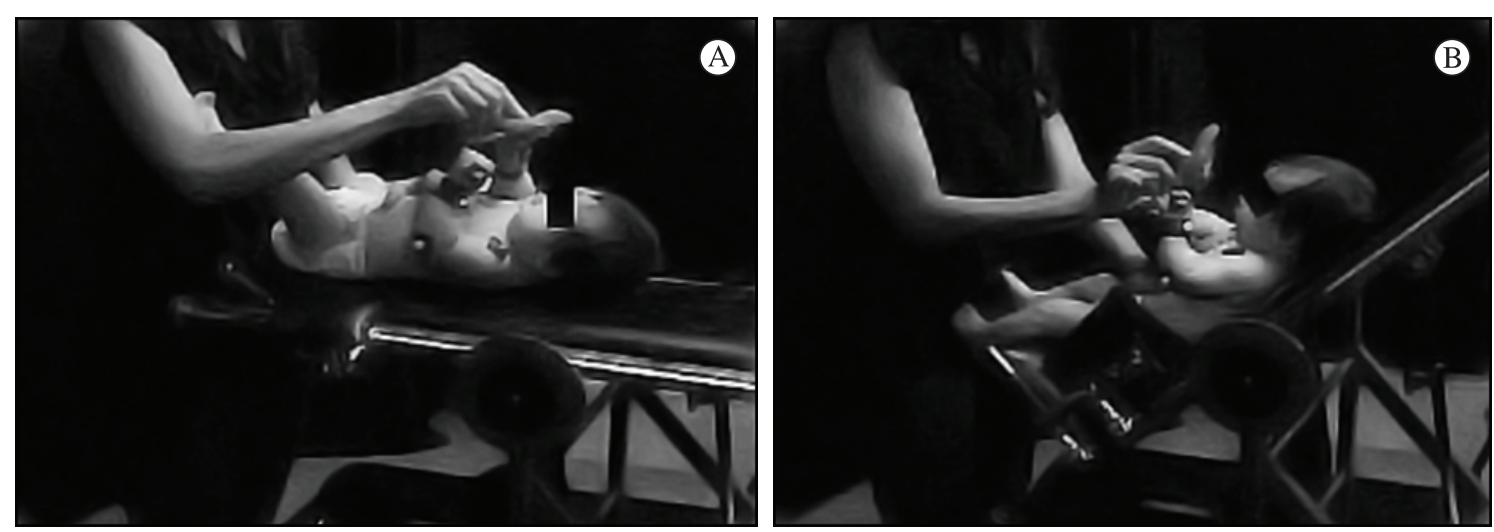

Figure 1. Supine position (A) and testing procedures in reclined position (B). 


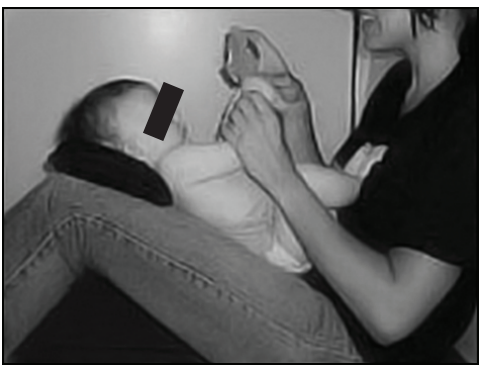

Activity 1

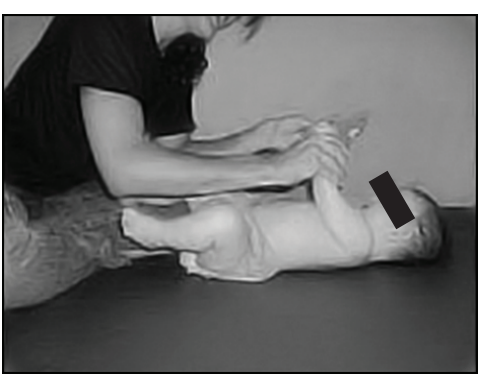

Activity 1

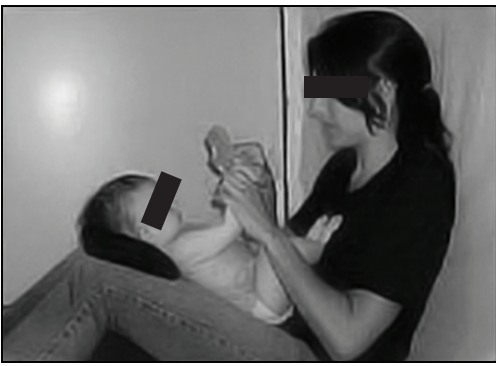

Activity 2

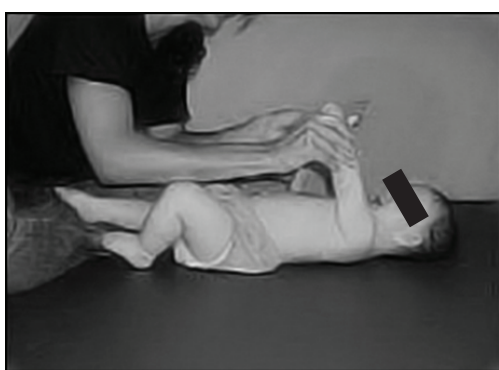

Activity 2

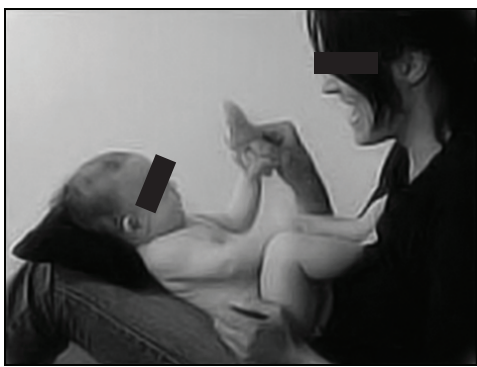

Activity 3

(B)

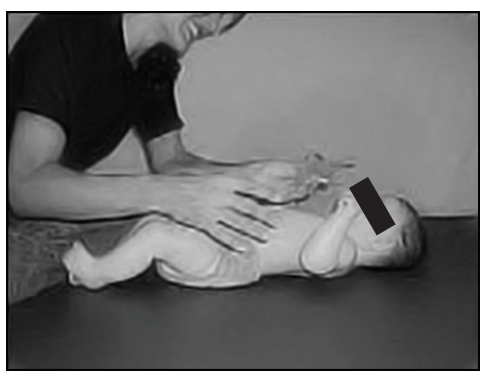

Activity 3

Figure 2. Training in the reclined position (A) and training in the supine position (B): activity 1; activity 2; activity 3.

Table 1. The training sessions, both in the supine and reclined seated positions, consisted of three activities.

Activity 1 The examiner held the object in one hand, at the midline and at the height of the xiphoid process of the infant within the visual field of the infant and with the other hand, led the hand of the infant to the object. This procedure was performed three times for the right hand and three times for the left hand (Figure 2A.1, 2B.1).

Activity 2 The examiner held the object in one hand, at the midline and at the height of the xiphoid process of the infant and with the other hand, held the one forearm of the infant to position the hand within their visual field for a few seconds. If the infant did not touch the object or explored it by hand spontaneously, the examiner performed tactile stimulation with the object in the hand of the infant. This procedure was performed three times for the right hand and three times for the left hand (Figure 2A.2 /Figure 2B.2).

Activity 3 The upper limbs of the infant were positioned along the body. The examiner performed tactile stimulation on one arm and forearm of the infant with the object and took the object to the midline. The examiner waited a few seconds to allow the infant to perform spontaneous uni- or multi-joint upper limb movements. Each time the infant touched the object, the examiner, with a smile, praised him/her. If the infant were to grasp the object, the examiner let him/her explore it. This procedure was performed three times for the right hand and three times for the left hand (Figure 2A.3/ Figure 2B.3).

the equation [number of agreements/ (number of agreements + number of disagreements) $] \times 100$.

\section{Spatio-temporal reaching variables}

The movement duration was defined as the difference in time between the beginning and end of the reaching movement ${ }^{2,12}$. The mean velocity was defined as the ratio between the distance traveled and the time spent along the movement $t^{2,3,37}$. The straightness index was defined as the ratio between the shortest distance that could be traveled in the path compared to the distance actually traveled by the hand. The closer the index was to 1, the straighter was the trajectory ${ }^{2,24,38}$. A movement unit was defined as the maximum velocity between two minimums ${ }^{2,3}$, with the difference being greater than $1 \mathrm{~cm} / \mathrm{s}^{3}$.

\section{Variables characterizing the sample}

Gross motor development was assessed by the AIMS, and the infant's raw score was determined (i.e., total AIMS score); the scores for each of the four subscales were calculated and added together. 
Body Weight was considered the total body weight in kilograms $(\mathrm{kg})$. Age at onset of reaching was considered the precise week that the infant acquired the reaching movement (in weeks).

\section{Statistical analysis}

A significance level $\alpha$ of 0.05 was adopted. All inferential procedures were preceded. The factors considered were group, position, assessment and the interaction among these components. Three variables (movement duration, mean velocity and straightness index) were submitted to analysis of variance (ANOVA) and multiple comparisons (Tukey corrections). For the movement unit, the nonparametric Friedman analysis of variance for two factors was performed, followed by the nonparametric t test, (sum of ranks) with Bonferroni adjustment. For variables characterizing the sample population (gross motor development, body weight and the age at onset of reaching) the statistical analysis was performed using the nonparametric Kruskal Wallis analysis of variance, followed by the nonparametric $t$ test with Bonferroni adjustment.

\section{Results}

\section{Group demographics}

There was no difference between the control group (12.6 \pm 0.7$)$, the group trained in the reclined position $(12.7 \pm 0.7)$ and the group trained in the supine position $(12.8 \pm 0.7)$ with regard to the AIMS score $\left(\chi^{2}=0.61\right.$; $\mathrm{p}=0.735)$. In relation to body weight, there was no difference $\left(\chi^{2}=2.12 ; \mathrm{p}=0.346\right)$ among the three groups (control group (6.81 kg \pm 0.8$)$, reclined training (6.28 $\mathrm{kg} \pm 0.6)$ and supine training (6.42 $\mathrm{kg} \pm 0.6)$. There was no difference $\left(\chi^{2}=2.12 ; \mathrm{p}=0.346\right)$ in the age at onset of reaching among the groups (control group (13.7 weeks \pm 1.6 ), reclined training (12.9 weeks \pm 0.7$)$ and supine training (13.1 weeks \pm 1.2$)$ ).

\section{Spatio-temporal reaching variables}

There were no differences in movement duration at the pre-training assessment in either the supine or reclined position $(\mathrm{F}[1,39]=2.4 ; \mathrm{p}=0.127)$ among the three groups. A significant difference based on the group factor was observed $(\mathrm{F}[2,39]=7.1 ; \mathrm{p}=0.012)$, where the group trained in the reclined position presented a shorter movement duration $(0.48 \mathrm{~s})$ compared to the other groups $(0.63 \mathrm{~s})$. There was also a significant difference between components of the group $\mathrm{x}$ position $\mathrm{x}$ assessment interaction $(F[15,39]=5.09 ; \mathrm{p}<0.001)$. For the group trained in the reclined position, a significant decrease was observed in the movement duration in the reclined position between the pre-training $(0.60 \mathrm{~s})$ and posttraining $(0.37 \mathrm{~s})$ tests. Similarly, the group trained in the supine position exhibited a significant decrease in the movement duration in the supine position between the pre-training $(0.79 \mathrm{~s})$ and post-training (0.56 s) tests (Figure 3 ).

There was no difference in mean velocity between the three groups at the pre-training assessment in either the supine or reclined position $(\mathrm{F}[1,40]=0.12$; $\mathrm{p}=0.883$ ). A significant difference was observed for the assessment factor $(F[1,40]=19.08 ; \mathrm{p}=0.0001)$, with significantly lower mean velocity values observed in the pre-training $(0.20 \mathrm{~m} / \mathrm{s})$ compared with the post-training assessments $(0.27 \mathrm{~m} / \mathrm{s})$. A

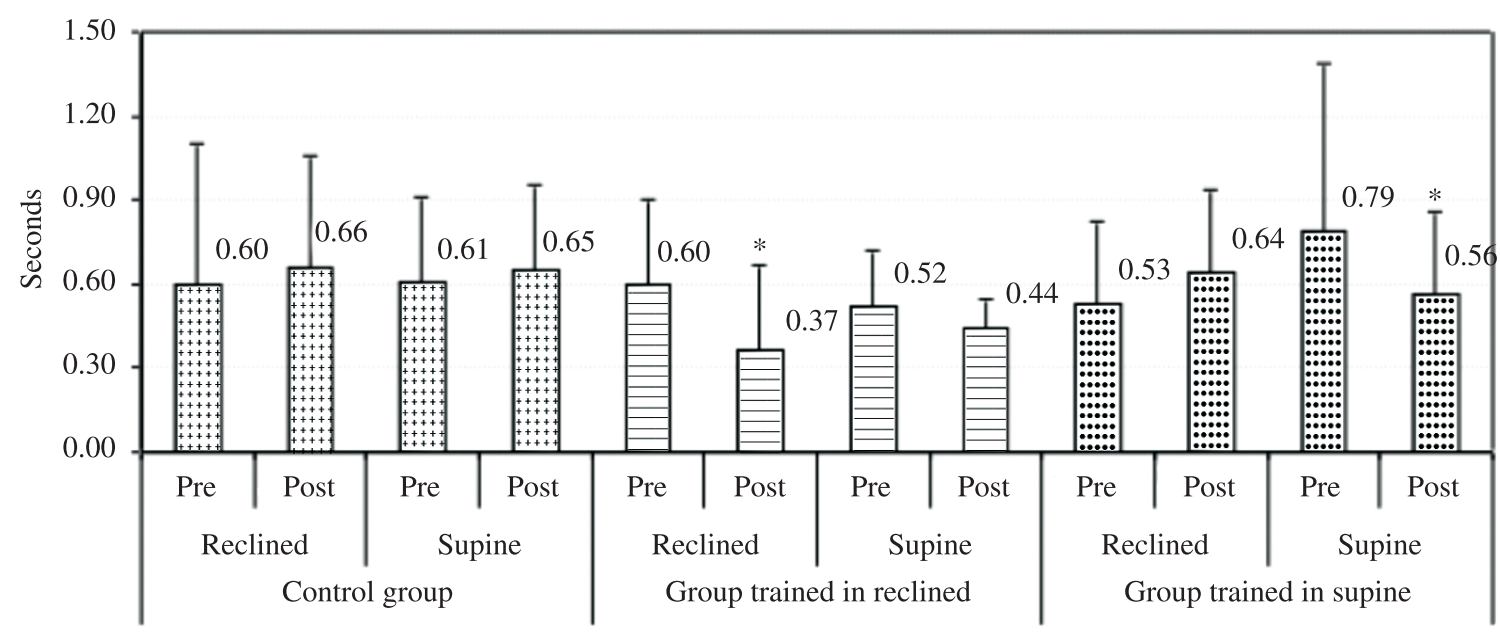

Figure 3. Mean values and standard deviation of the movement duration (in seconds) variable at pre- and post-training assessments in the reclined and supine positions in the three groups of infants. 
significant difference for group $\mathrm{x}$ position was observed $(\mathrm{F}[2,40]=4,9 ; \mathrm{p}=0.0116)$. When assessed in the reclined position, the mean velocity of the group trained in the reclined position $(0.24 \mathrm{~m} / \mathrm{s})$ was higher $(\mathrm{p}<0.05)$ than in the control group $(0.18 \mathrm{~m} / \mathrm{s})$ and the group trained in the supine position $(0.19 \mathrm{~m} / \mathrm{s})$, and no group $\mathrm{x}$ position $\mathrm{x}$ assessment interaction was observed.

For the straightness index, there was no difference at the pre-training assessment in either the supine or the reclined position $(\mathrm{F}[1,40]=0.61 ; \mathrm{p}=0.564)$ among the three groups. A significant difference was observed for the group factor $(F[2,40]=3.84$; $\mathrm{p}=0.030$ ), with greater mean straightness index values in the group trained in the supine position $(0.55)$ compared with the group trained in the reclined position (0.48). No group $\mathrm{x}$ position $\mathrm{x}$ assessment interaction was observed.

For the movement unit variable, there were also no differences between the three groups at the pre-training assessment in either the supine or reclined position $\left(\chi^{2}=10.13 ; \mathrm{p}=0.2752\right)$. The Friedman's test showed a group $\mathrm{x}$ assessment $\mathrm{x}$ position interaction $\left(\chi^{2}=8.16 ; \mathrm{p}=0.0432\right)$, indicating a significant difference. In the group trained in the reclined position, there was a significant increase in the number of movement units of reaches performed in the supine position between the pre-training (2.06) and post-training (2.62) assessments (Figure 4).

\section{Discussion}

This study investigated the influence of a short training session on spatio-temporal parameters of reaching at the onset of goal-directed reaching in full-term infants. The spatio-temporal parameters of reaching were evaluated shortly after the onset of this ability so that the effects of spontaneous practice would not interfere with the results. Another important aspect of this study was that the infants did not differ in gross motor function, body weight or age at onset of reaching or in pre-training spatial-temporal variables, demonstrating that the three groups were similar to each other.

Our first hypothesis was that the specific training would improve spatio-temporal reaching parameters. Our results demonstrated that both training positions were effective in promoting shorter reaches in the specific position in which the training was conducted, confirming the positive influence of the training. In previous studies, infants who received specific reaching training (2-3 weeks) showed improvement in a number of performance variables, including an increased amount of time spent with the hand near the object, a closer position of the hands to the object, an increased number of hand contacts with the object, a greater number of bilateral reaches and more open handed touches ${ }^{15,19}$. In our study, we believe that this change occurred because the requested task was only to touch the object, without necessarily grasping it. In this task, there was no need for refined and fluent movements, such as those observed in mature reaching, with a higher straightness index and fewer movement units ${ }^{12,14,39}$.

However, we must also consider that due to the very young age of the infants (average age of 3.5 months), the number of movement units in all conditions was high, accompanied by a low straightness index. This fact suggests that these young infants were still unable to control their upper limbs to perform a straight and fluent reach and were still in the primary variability stage of learning to reach. We

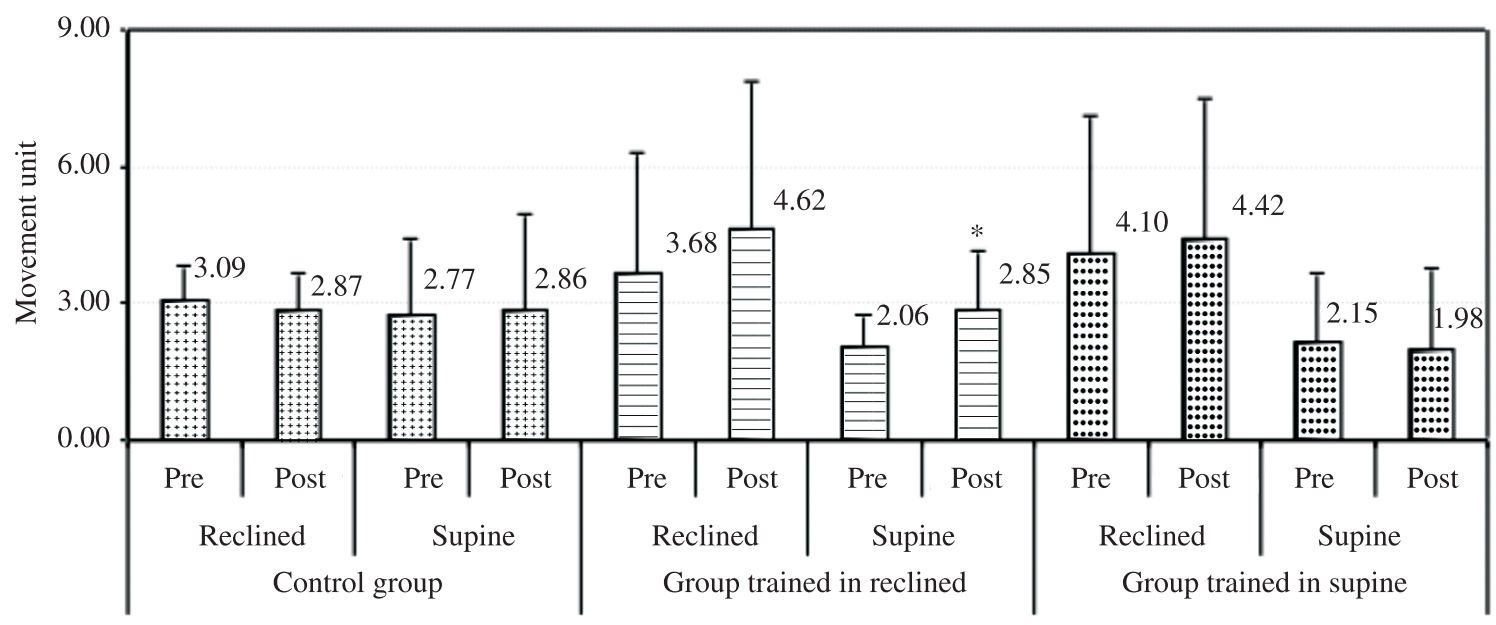

Figure 4. Median and quartile deviation of movement units at pre- and post-training assessments in the reclined and supine positions in the three groups of infants. 
believe that because these variables reflect complex behaviors, it is possible that they are not influenced by a single training session. Although other studies have reported changes in the straightness index and adjustment index ${ }^{12-14}$ through spontaneous practice, these changes occurred from 4 to 7 months of age. According to Edelman ${ }^{40}$, it is the process of continuous movement practice that allows the infant to modify, select and stabilize the patterns that best suit the task demands. Thus, it could be inferred that the selection of more efficient motor standards requires a greater number of sessions for coordination of straighter and more precise movements.

Another important factor was that the infants trained in the reclined position exhibited a shorter movement duration and higher mean velocity (i.e., shorter and faster reaches) when compared to other groups tested in the reclined position. According to Thelen et al. ${ }^{1}$, infants who performed movements with higher velocity need more tension to move a joint faster for a given distance. These authors proposed that infants are creating task-specific reaching strategies by adjusting the tension and the energy they deliver to the reach ${ }^{1}$. We suggest that when trained and assessed in a reclined position, the infants had head and trunk support, providing stability and thus lower postural requirements, allowing shorter and faster reaches. Thus, providing postural stability to young infants facilitates the performance of more reaching movements ${ }^{19,41-43}$, and in this position, the infants are capable of producing the amount of force and torque required to defy gravity and better control their upper limbs ${ }^{11,24,32}$.

Regarding the second hypothesis, there were no changes in spatio-temporal parameters from one position to another, as evidenced by the fact that infants trained in the reclined position presented shorter reaches post-training only in the reclined position, while infants trained in the supine position presented shorter reaches only in the supine position. These results corroborate reports that the learning of motor tasks is highly context-specific ${ }^{21}$, affecting only the subset of neural inputs that are active under specific stimulus conditions ${ }^{44}$. Thus, the training constantly strengthens existing and/or forms new cortical neuronal networks ${ }^{6-8,10}$ resulting in an improvement in the function and motor abilities ${ }^{45,46}$. In this context, there is evidence that in young infants, interventions to improve motor patterns had a higher beneficial effect when performed in a specific training context ${ }^{17-19}$. In addition, a significant increase in the number of movement units was observed in the group trained in the reclined position in the supine position post-training, demonstrating that infants trained in the reclined position presented no improvement in parameters from training when tested in the supine position. We believe that when assessed in a supine position, infants who were trained in a reclined position increased the variability of their reaching strategies to solve the additional biomechanical challenges, such as forces acting on the upper limbs imposed by the supine position ${ }^{11,12}$, resulting in an increase in the number of movement units to reach the object.

\section{Limitations and conclusions}

In conclusion, a short-duration session training was effective in promoting shorter reaches in infants at the onset of goal-direct reaching. This change may have occurred because the task required was only to touch the object, without necessarily grasping it. Thus, there was no need for refined and fluent movements, such as those observed in mature reaching, which involves a higher straightness index and fewer movement units. In addition, infants trained in the reclined position presented shorter movement duration and higher mean velocity when tested in the reclined position. Thus, we infer that training and testing in the reclined position is associated with reduced demand for muscle torque at the beginning of the movement and lower postural requirements, and consequently, training in the reclined position allowed shorter and faster reaches. The study also verified that shorter reaches were specific to the position in which the infants were trained, and thus, we could infer that the learning of motor tasks is highly context-specific.

Limitations of the study included the fact that the control group remained in their parents' laps during the interval between assessments instead of being positioned in a supine position on the mat or reclined in the physical therapist's lap. Additionally, the experimental results do not allow the determination of any long-term effects of the training. It is possible that changes in reaching behavior after training remained for only a short period. Because these results provide empirical support for clinical practice about motor behavior, other studies on reach training are warranted.

\section{Acknowledgments}

The parents and infants for participating in the study and are grateful for the support of researchers from the Neuropediatrics Sector of UFSCar for their assistance with data collection and data analysis. The 
Raquel de Paula Carvalho for support provided for this manuscript.

The Coordenação de Aperfeiçoamento de Pessoal de Nível Superior (CAPES), Brazil, of the Fundação de Amparo à Pesquisa do Estado de São Paulo (FAPESP), Brazil, and Conselho Nacional de Desenvolvimento Científico e Tecnológico (CNPq), Brazil.

\section{References}

1. Thelen E, Corbetta D, Kamm K, Spencer J, Schneider K, Zernicke RF. The transition to reaching: Mapping intention and intrinsic dynamics. Child Dev. 1993;64(4):1058-98. PMid:8404257. http://dx.doi.org/10.2307/1131327

2. von Hofsten C. Structuring of early reaching movements: a longitudinal study. J Mot Behav. 1991;23(4):280-92 PMid:14766510. http://dx.doi.org/10.1080/00222895.1 991.9942039

3. Thelen E, Corbetta D, Spencer JP. Development of reaching during the first year: role of movement speed. J Exp Psychol Hum Percept Perform. 1996;22(5):1059-76. PMid:8865616. http://dx.doi. org/10.1037/0096-1523.22.5.1059

4. Van der Fits IB, Flikweert ER, Stremmelaar EF, Martijn A, Hadders-Algra M. Development of postural adjustments during reaching in preterm infants. Pediatr Res. 1999;46(1):1-7. PMid:10400126. http://dx.doi. org/10.1203/00006450-199907000-00001

5. Konczak J, Dichgans J. The development toward stereotypic arm kinematics during reaching in the first 3 years of life. Exp Brain Res. 1997;117(2):346-54. http:// dx.doi.org/10.1007/s002210050228

6. Sporns O, Edelman GM. Solving Bernstein's Problem: a proposal for the development of coordinated movement by selection. Child Dev. 1993;64(4):960-81. http://dx.doi. org/10.2307/1131321

7. Hadders-Algra M. The Neuronal Group Selection Theory: a framework to explain variation in normal motor development. Dev Med Child Neurol. 2000;42(8):56672. PMid:10981936. http://dx.doi.org/10.1017/ S0012162200001067

8. Hadders-Algra M. The Neuronal Group Selection Theory: promising principles for understanding and treating developmental motor disorders. Dev Med Child Neurol. 2000;42(10):707-15. PMid:11085302. http://dx.doi. org/10.1017/S0012162200001316

9. Piek JP. The role of variability in early motor development. Infant Behav Dev. 2002;25(4):452-65. http://dx.doi. org/10.1016/S0163-6383(02)00145-5

10. Heineman KR, Middelburg KJ, Hadders-Algra M. Development of adaptive motor behaviour in typically developing infants. Acta Paediatr. 2010;99(4):618-24. PMid:20050831. http://dx.doi. org/10.1111/j.1651-2227.2009.01652.x

11. Savelsbergh GJ, van der Kamp J. The effect of body orientation to gravity on early infant reaching. J Exp Child
Psychol. 1994;58(3):510-28. PMid:7844502. http://dx.doi org/10.1006/jecp.1994.1047

12. Carvalho RP, Tudella E, Savelsbergh GJP. Spatiotemporal parameters in infant's reaching movements are influenced by body orientation. Infant Behav Dev. 2007;30(1):26-35. PMid:17292777. http://dx.doi. org/10.1016/j.infbeh.2006.07.006

13. Rocha NACF, Silva FPS, Tudella E. The impact of object size and rigidity on infant reaching. Infant Behav Dev. 2006;29(2):251-61. PMid:17138280. http://dx.doi. org/10.1016/j.infbeh.2005.12.007

14. Toledo AM, Tudella E. The development of reaching behavior in low-risk preterm infants. Infant Behav Dev. 2008;31(3):398-407. PMid:18289691. http://dx.doi. org/10.1016/j.infbeh.2007.12.006

15. Lobo MA, Galloway JC, Savelsbergh GJ. General and task-related experiences affect early object interaction Child Dev. 2004;75(4):1268-81. PMid:15260877. http:// dx.doi.org/10.1111/j.1467-8624.2004.00738.x

16. Heathcock JC, Lobo M, Galloway JC. Movement training advances the emergence of reaching in infants born at less than 33 weeks of gestational age: a randomized clinical trial. Phys Ther. 2008;88(3):310-22. PMid:18096650. http://dx.doi.org/10.2522/ptj.20070145

17. Zelazo NA, Zelazo PR, Cohen KM, Zelazo PD. Specificity of practice effects on elementary neuromotor patterns. Dev Psychol. 1993;29(4):686-91. http://dx.doi. org/10.1037/0012-1649.29.4.686

18. Blauw-Hospers CH, Hadders-Algra M. A systematic review of the effects of early intervention on motor development. Dev Med Child Neurol. 2005;47(6):42132. PMid:15934492. http://dx.doi.org/10.1017/ S0012162205000824

19. Lobo MA, Galloway JC. Postural and objectoriented experiences advance early reaching, object exploration, and means - end behavior. Child Dev. 2008;79(6):1869-90. PMid:19037955. http://dx.doi. org/10.1111/j.1467-8624.2008.01231.x

20. Karni A, Meyer G, Jezzard P, Adams MM, Turner R, Ungerleider LG. Functional MRI evidence for adult motor cortex plasticity during motor skill learning. Nature. 1995;377(6545):155-8. PMid:7675082. http://dx.doi. org/10.1038/377155a0

21. Karni A, Meyer G, Rey-Hipolito C, Jezzard P, Adams $\mathrm{M}$, Tuner R, et al. The acquisition of skilled motor performance: fast and slow experience-driven changes in primary motor cortex. Proc Natl Acad Sci USA. 1998;95(3):861-8. PMid:9448252 PMCid:PMC33809. http://dx.doi.org/10.1073/pnas.95.3.861

22. Ungerleider LG, Doyon J, Karni A. Imaging brain plasticity during motor skill learning. Neurobiol Learn Mem. 2002;78(3):553-64. PMid:12559834. http://dx.doi. org/10.1006/nlme.2002.4091

23. Kleim JA, Hogg TM, Van den Berg PM, Cooper NR, Bruneau R, Remple M. Cortical synaptogenesis and motor map reorganization occur during late, but not early, phase of motor skill learning. J Neurosci. 2004;24(3):628-33. PMid:14736848. http://dx.doi. org/10.1523/JNEUROSCI.3440-03.2004 
24. Carvalho RP, Tudella E, Caljouw SR, Savelsbergh GJ. Early control of reaching: effects of experience and body orientation. Infant Behav Dev. 2008;31(1):2333. PMid:17658609. http://dx.doi.org/10.1016/j. infbeh.2007.06.001

25. American Academy of Pediatrics. The Apgar Score. Pediatrics. 2006;117(4):1444-7 PMid:16585348. http:// dx.doi.org/10.1542/peds.2006-0325

26. World Health Organization - WHO. Multicentre Growth Reference Study Group. WHO Child Growth Standards based on length/height, weight and age. Acta Paediatr Suppl. 2006;450:76-85. PMid:16817681.

27. Piper MC, Darrah J. Motor Assessment of the Developing Infant. Philadelphia: W B Saunders; 1994.

28. Barros RML, Brenzikofer R, Leite NJ, Figueiroa PJ. Desenvolvimento e avaliação de um sistema para análise cinemática tridimensional de movimentos humanos. Rev Bras Engenh Biomed. 1990;15:79-86.

29. Figueroa PJ, Leite NJ, Barros RML. A flexible software for tracking of markers used in human motion analysis. Comput Methods Programs Biomed. 2003;72(2):155-65. http://dx.doi.org/10.1016/S0169-2607(02)00122-0

30. Carvalho RP, Tudella E, Barros RML. Utilização do sistema Dvideow na análise cinemática do alcance manual de lactentes. Rev Bras Fisioter. 2005;9(1):41-7.

31. Prechtl HFR, Beintema DJ. The neurological examination of the full-term newborn infant. In: Clinics in developmental medicine. London: Lavenham Press; 1964.

32. Toledo AM, Soares DA, Tudella E. Proximal and distal of reaching behavior in preterm infants. J Mot Behav. 2011;43(2):137-45. PMid:21400327. http://dx.doi.org/1 0.1080/00222895.2011.552076

33. Soares DA, Cunha AB, Barbosa GO, Carvalho RP, Tudella E. Efeito dos treinos de alcance manual e de controle postural sobre o alcance em lactentes: estudo de caso controle. Ter Man. 2010;8(40):89-92.

34. Del Rey P, Whitehurst M, Wood JM. Effects of experience and contextual interference on learning and transfer by boys and girls. Percept Mot Skills. 1983;57: 241-42. http:// dx.doi.org/10.2466/pms.1983.57.1.241

35. Jarus T, Gutman T. Effects of cognitive processes and task complexity on acquisition, retention and transfer of motor skills. Can J Occup Ther. 2001;68(5):280-9. http://dx.doi. org/10.1177/000841740106800504

36. Savion- Lemieux T, Penhune VB. The effect of practice pattern on the acquisition, consolidation, and transfer of visual-motor sequences. Exp Brain Res.
2010;204:271-81. PMid:20526710. http://dx.doi. org/10.1007/s00221-010-2311-6

37. Mathew A, Cook M. The control of reaching movements by young infants. Child Dev. 1990;61:1238-57. http:// dx.doi.org/10.2307/1130891

38. von Hofsten C. Development of visually directed reaching: the approach phase. J Hum Mov Stud. 1979;5:160-8.

39. Konczak J, Borutta M, Topka H, Dichgans J. The development of goal-directed reaching in infants: hand trajectory formation and joint torque control. Exp Brain Res. 1995;106(1):156-68. PMid:8542971. http://dx.doi. org/10.1007/BF00241365

40. Edelman GM. Neural Darwinism. New York: Basic Books; 1987.

41. Out L, Van Soest AJ, Savelsbergh GJP, Hopkins B. The effect of posture on early reaching movements. J Mot Behav. 1998;30(3):260-72. PMid:20037083. http://dx.doi. org/10.1080/00222899809601341

42. Rochat $P$, Goubet N. Development of sitting and reaching in 5- to 6-month-old infants. Infant Behav Dev. 1995; 18(1):5368. http://dx.doi.org/10.1016/0163-6383(95)90007-1

43. Saavedra S, Joshi A, Woollacott M, Donkelaar PV. Eye hand coordination in children with cerebral palsy. Exp Brain Res. 2009;192(2):155-65. PMid:18830589 PMCid:PMC2800126. http://dx.doi.org/10.1007/ s00221-008-1549-8

44. Gilbert CD, Li W, Piech V. Perceptual learning and adult cortical plasticity. J Physiol. 2009;587(12):2743-51. PMid:19525560 PMCid:PMC2718234. http://dx.doi. org/10.1113/jphysiol.2009.171488

45. Barbro J. Brain plasticity and stroke rehabilitation. Stroke. 2000;31(1):223-30. http://dx.doi.org/10.1161/01. STR.31.1.223

46. Green S, Grierson LE, Dubrowski A, Carnahan H. Motor adaptation and manual transfer: insight into the persistent nature of sensorimotor representations. Brain Cogn. 2010;72(3):385-93. PMid:20034721. http://dx.doi. org/10.1016/j.bandc.2009.11.006

\section{Correspondence}

\section{Andréa Baraldi Cunha}

Rua Vitor Manoel de Souza Lima, 328 - Apto. 17

CEP 13561-020, São Carlos, SP, Brasil

e-mail: andreabaraldi@gmail.com 
